\title{
Online Collaborative Writing via Google Docs: Case Studies in the EFL Classroom
}

\author{
Nakhon Kitjaroonchai \\ School of Foreign Languages, Suranaree University of Technology, Nakhon Ratchasima, Thailand \\ Suksan Suppasetseree \\ School of Foreign Languages, Suranaree University of Technology, Nakhon Ratchasima, Thailand
}

\begin{abstract}
This article reported a case study investigating small group interaction patterns in online collaborative writing tasks and factors influencing team collaborations. Participants included six Asian EFL university students who formed two small groups and were engaged in two online collaborative writing tasks via Google Docs. Data collection included the participants' use of writing change functions and language functions during the collaborative writing processes revealed through Google Docs archives and collaborative essays. Semi-structured interviews were employed to examine factors influencing small group collaborations. The findings revealed that the two teams exhibited divergent interaction patterns, but the patterns of interaction remained consistent within each group across both tasks. The qualitative content analysis showed factors that affected team collaborations were individual goals, learners' English proficiency, individual roles, and the use of collaborative agency. The findings may help elucidate the divergence of online collaborative writing and provide insightful information for instructors to design collaborative writing activities and assist EFL learners in the co-construction of writing tasks.
\end{abstract}

Index Terms - online collaborative writing, interaction patterns, EFL learners, language functions, writing change functions, team collaborations

\section{INTRODUCTION}

Collaborative writing $(\mathrm{CW})$ has been broadly implemented in EFL classrooms for the last two decades due to its potential to improve writing quality (Abe, 2020; Limbu \& Markauskaite; Storch, 2013); to enhance writing accuracy (Chen, 2019; Dobao, 2014); and to stimulate constructive ideas and meaning-making trajectories (Alghasab, Hardman, \& Handley, 2019). In addition, CW provides opportunities for interactive and collective writing in the target language (Hsu, 2020).

Previous studies (e.g., Hsu, 2020; Li \& Kim, 2016; Li \& Zhu, 2017; Wang, 2019) reported that learners in small groups exhibited distinctive interaction patterns while engaging in collaborative tasks. For example, Li \& Kim (2016) found that two small groups of ESL graduate students undertaking English for Academic Purposes (EAP) produced distinctive patterns of interaction, and those interactional patterns shifted within each group across tasks. In another study, Wang (2019) found that two small groups of Chinese university students engaging in two collaborative argument essays shifted their interaction patterns when tasks were set in synchronous writing: one group was willing to engage more in real-time collaboration, whereas the other group demonstrated less directional communication. More recently, Hsu (2020) investigated if task complexity affected peer interaction on web-based asynchronous CW tasks in an EFL classroom context at a Taiwanese university. She found that the interaction patterns remained stable across tasks. While helpful, these studies were conducted in settings where students share the same first language; scant research has explored factors influencing collaborative team efforts university students from culturally and linguistically diverse backgrounds. What makes the team collaborate more collectively? This warrants further examination given the increasing mobility of international students. Therefore, the objectives of this study were to investigate small group interaction patterns and factors that influence team collaborations.

\section{LITERATURE REVIEW}

\section{A. Online Collaborative Writing with Google Docs}

There has been a growing interest in online collaborative writing (OCW) due to the rapid development of new technologies that support individual and group writing. With the advancement of web 2.0 technologies and social software available for education, writing tasks are becoming less self-directed to be focused more on collaboration. This is because collaborative work yields benefit in text production (Dobao, 2014; McDonough \& De Vleeschauwer, 2019; Storch, 2013). In addition, active collaboration has proven to bring cognitive advantage and development (Hsu, 2020).

The OCW tools such as Google Docs (GD) and Wiki are writing tools used extensively in education (Andrew, 2019; Lee \& Hassell, 2021). GD is designed to be highly interactive, which permits writers to contribute or edit their text 
synchronously in real-time or asynchronously, and such convenience was not available in a conventional writing classroom (Woodrich \& Fan, 2017). Furthermore, researchers (e.g., Krishnan et al., 2019; Zioga \& Bikos, 2020) reported that web-based word processors like GD could stimulate students' motivation and engagement in group tasks as well as in individual writing development. Through synchronous discussions or asynchronous online discussions, learners can also enhance their critical thinking skills and written communication skills (Afify, 2019). Although OCW has sparked the interest of language educators and L2 writing researchers due to its potentiality for enhancing writing skills (Andrew, 2019; Yanguas, 2020), there is little research on the OCW classrooms with learners from culturally diverse backgrounds.

\section{B. Wring Change Functions and Language Functions in Peer Interaction}

Writing change functions were first reported by Mak and Coniam (2008) when they explored how ESL learners coconstructed texts on a wiki platform. The researchers identified categories such as adding, correcting, expanding ideas, and reorganizing ideas. Similarly, in Li's (2013) study on wiki-based CW in a small group, five major types of writing change functions (WCFs) were discovered. They were addition (adding or contributing new texts initially composed by peers or self); deletion (deleting content or texts initially written by peers or self); rephrasing (stating ideas in different words, made on peers' or self-text); reordering (reorganizing ideas by moving texts around content, made on peers or self-text); and correction (correcting grammatical errors or mistakes on language). Changes of meaning in CW tasks have also been examined, such as that by Kessler, Bikowski, and Boggs (2012). Their study found that the students, who were in a midwestern university in the USA, focused on meaning changes (e.g., text that contributed to meaning were added, deleted, or replaced) than form (e.g., capitalization, part of speech, punctuation, pluralization, spelling, tense, spacing, and grammatical changes). This might be because the participants possessed a high level of language proficiency, and they focused more on the global level (content and organization) rather than the local level (grammatical mistakes or language mechanism).

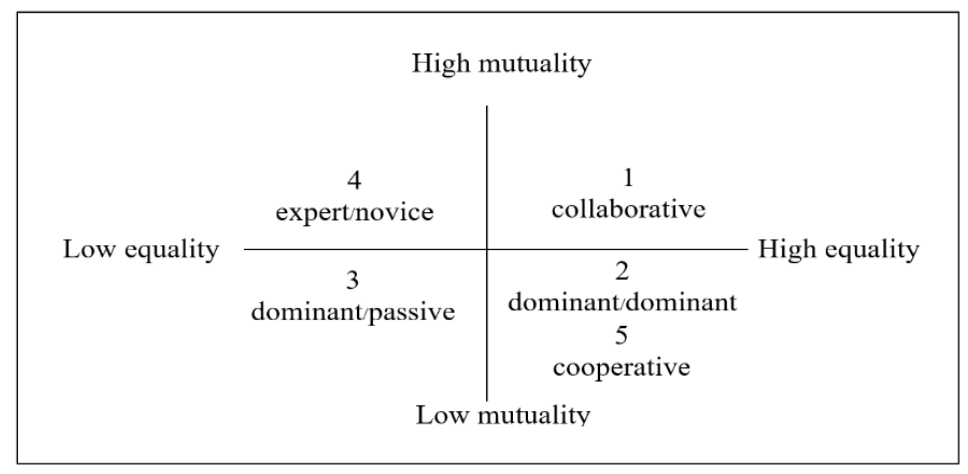

Figure 1. Model of Dyadic Interaction (Storch, 2013)

Another line of inquiry concerning students' revision behaviors is language functions (LFs). LFs mirrors how learners use the target language as a mediating tool to interact with partners (see Elabdali \& Arnold, 2020; Li \& Kim, 2016; Zhang 2019). Frequently used LFs include acknowledging, agreeing, clarifying, confirming, disagreeing, elaborating, eliciting, justifying, questioning, requesting, and suggesting (Li, 2014). These LFs inevitably shapes the patterns of interaction, which influence writing products (Hsu, 2020; Li \& Zhu, 2017). Storch's (2013) earlier study endorsed five distinctive patterns of interaction: 1) collaborative, 2) cooperative, 3) dominant/dominant, 4) dominant/passive, and 5) expert/novice. Storch's dyadic interaction model is defined by member involvement with one another, either equality or mutuality. Equality refers to the contribution level and the extent to which the contributor endeavors to occupy their position in text contribution, whereas mutuality represents the degree of contributor's engagement with others' work through providing comments or editing texts. Storch's model of dyadic interaction is illustrated in Figure 1.

The pattern in Quadrant 1 is labeled collaborative, which depicts moderate to high levels of equality and mutuality, where members contribute and engage with each other's work. In Quadrant 2, there are two patterns of interaction: dominant/dominant and cooperative. The dominant/dominant pattern may show moderate to high equality but low mutuality. In other words, group members contribute but may also compete for control over the task, yet pay less attention to other's contributions (Storch, 2013). Cooperative, on the other hand, sees that members proportionally contribute to the task, and their equality may appear moderate to high, but their mutuality is relatively low as work is divided with minimal engagement with other's texts. Quadrant 3 - dominant/passive - refers to medium to low levels of equality and mutuality, which implies that one member in the group takes control while others are passive participants. Lastly, Quadrant 4 depicts moderate to low equality but moderate to high mutuality. The pattern emerging from this quadrant is identified as expert/novice, in which one member in the group contributes more than others and plays a dominant role as an expert. Unlike the dominant/passive, in which the main contributor fails to provide support to other 
members, the dominant member in the expert/novice pattern, on the contrary, supports the team members throughout the CW process (Storch, 2013).

\section{Scaffolding Strategies}

In collaborative tasks, learners may use scaffolding strategies. The notion of scaffolding is derived from the earlier work of Vygotsky (1978), who posited that learning occurs when learners interact with their social environment, particularly when they engage with more capable peers. To some scholars (e.g., Hammond \& Gibbon, 2005; Prichard \& Woollard, 2010; Van Lier, 2004), scaffolding is a means of assistance granted by someone who can support or assist in the process of acquiring knowledge and enhancing the learning experience. Scaffolding is perceived to be "a form of support for the development and learning of young learners" (Rasmussen, 2001, p.570) in knowledge building with the assistance of teachers or peers who provide essential tools to enhance the learning experience (Mahan, 2020). According to Hanjani and $\mathrm{Li}$ (2014), learners in small groups use scaffolding negotiations to support their peers while co-constructing texts. Furthermore, when scaffolding is provided collectively, it should conform to three conditions: drawing peers' attention to the problem, providing a solution(s) or alternative(s), and enhancing the scope of the taskrelated issue, so that the peers could revise their writing for better quality. For this reason, OCW tasks are perceived to be an effective pedagogical approach to escalate scaffolding in the language classroom.

\section{Research Questions}

As revealed in previous studies, CW styles and interaction patterns are shaped by individual member's contributions towards the task. Some groups or pairs demonstrated consistent patterns of interaction despite the change in tasks or change in writing modes, whereas some exhibited shifts in interaction patterns. Nonetheless, scant research to date has explored how EFL learners with different cultural backgrounds interact with one another in CW tasks and what factors may influence their collaborations. With this as a gap, this study investigated small group interaction patterns and factors that influence team collaborations. The following research questions guided the study.

1) What patterns of interaction occur when EFL learners in small groups engage in OCW tasks in Google Docs?

2) What are the factors that influence small group collaborations?

\section{METHOdOLOGY}

Our study is structured as an embedded case study (see Yin, 2018), which may be defined as examining several subcases with its own bounded system but embedded within the same study site (see Li, 2014). The sub-cases were bounded by time (two collaborative tasks and CW activities spanning 10 weeks) and setting (a composition course offered at an international university). In this current study, we explored small group interaction patterns and factors influencing team collaborations of EFL university students engaging in two OCW tasks using GD.

\section{A. Participants}

The participants were six EFL first-year university students selected from 18 students enrolled in an English composition course spanning one semester at an international university in central Thailand. These participants were chosen based on three criteria: (1) diversity of cultural backgrounds, (2) members in the group were varied in English language proficiency, and (3) all members were off-campus during the time of data collection due to the COVID-19 pandemic situation. The six participants selected for this case study were from five different countries in Southeast Asia, namely, Cambodia (1), Malaysia (1), Myanmar (1), the Philippines (1), and Thailand (2). Students' English proficiency ranged from pre-intermediate to advanced [comparable to A2 - C1 based on the Common European Framework of Reference for Languages (CEFR) scale] as reported by their IELTS band scores by the University Admission and Records Office.

\section{B. Group Formation}

Participants were divided into two groups. A reason for forming a small group of three members has been recommended to be more effective as it reduces the risk of slacking off from group work (Dobao, 2014). Each group was allowed to form its own team, with at least one member of a different nationality, and the members' language proficiency levels should be heterogeneous. Group members were informed that they could withdraw from this study at any time. In total, six groups were formed; however, two groups were selected for the case study as they met the three criteria identified above. The profile of the participants involved in the case study is presented in Table 1.

TABLE 1

PROFILE OF THE PARTICIPANTS

\begin{tabular}{|c|c|c|c|c|c|c|}
\hline Group & Pseudonym & Gender & Nationality & $\begin{array}{c}\text { Language proficiency level } \\
\text { (self-evaluation) }\end{array}$ & $\begin{array}{l}\text { IELTS overall } \\
\text { band score }\end{array}$ & Major of Study \\
\hline \multirow{3}{*}{ G1 } & Noah & Male & Filipino & Advanced & 7.5 & Public Health \\
\hline & Sopa & Female & Cambodian & Intermediate & 5.5 & Education \\
\hline & Samart & Male & Thai & Pre-intermediate & 4.0 & English \\
\hline \multirow{3}{*}{$\mathrm{G} 2$} & Aung Win & Male & Myanmar & Intermediate & 5.5 & Education \\
\hline & Danudet & Male & Thai & Pre-intermediate & 4.0 & Religious Studies \\
\hline & Tommy & Male & Malaysian & Upper-intermediate & 6.5 & Management \\
\hline
\end{tabular}




\section{Collaborative Writing Tasks}

The researchers constructed two collaborative lesson plans using the course textbook "College Writing Skills with Readings" by Langan and Albright (2019). The two CW lessons consisted of descriptive and argumentative essays. A significant reason for choosing these two types of essays was that a descriptive essay has distinctive characteristics that learners employ rich adjectives to draw sensory details and vivid impressions to readers, and it is perceived to be one of the easiest forms of academic writing. On the other hand, an argumentative essay is perceived to be difficult as it requires a writer to raise a debatable issue, state a point of view, and defend the point with evidence to persuade readers (Wingate, 2012). Therefore, the researchers selected these two writing genres (the least challenging and the most challenging) to explore how small groups interacted while performing group work. Each team was allowed to complete each CW task in GD in three weeks.

\section{Data Collection Procedure}

In the first week of the research timeframe, the principal researcher conducted a three-hour orientation for the participants to familiarize them with working in GD and introduced essential features for collaboration. In the second week, small groups were formed, and the researchers explained the informed consent form for participating in the study voluntarily. Learners signed the consent form that same week. In week 3, the participants started their first CW task. In week 6, they did the second task. Finally, in week 10, the researchers conducted semi-structured interviews via Zoom. Each interview lasted for about 25-30 minutes.

\section{E. Data Coding and Analysis}

The work of Li and Kim (2016) was used to identify WCFs and LFs and to determine degrees of equality and mutuality. Equality was measured in terms of (1) frequent use of WCFs and LFs shown in the GD revision history and (2) the percentage of text contributions. Mutuality was determined by (1) LFs on initiating versus responding acts, (2) comparing the instances of WCFs on self-contributed text and WCFs on others' text, all of which was recorded in the GD archives. Frequency counts of WCFs and LFs that each member produced along with the number of text contributions were compared to measure the interaction pattern as guided by Storch's (2013) model of dyadic interaction. Balanced contributions, including WCFs, LFs, and percentage of text contributions, marked high equality, while unbalanced contributions implied low equality. High mutuality was observed through frequent use of responding acts to initiating LFs, and WCFs made on other's texts. This analysis would address the first research question. Semi-structured interviews were employed to address the second research question on factors influencing team collaborations. The researchers analyzed this data qualitatively using content analysis through coding, categorizing, and emerging themes that helped explain team collaborations. The researchers coded $20 \%$ of the data both in WCFs and LFs produced by each member in the group to establish inter-rater reliability and inter-rater agreement. The results of Cohen's Kappa reliability index analysis reached $90 \%$ for WCFs and $86 \%$ on LFs. Any disagreements were resolved through discussion. Likewise, the qualitative data from semi-structured interviews were coded, categorized, and the researchers identified emerging themes from the qualitative content analysis. The taxonomy of WCFs and LFs is shown in Tables 2 and 3.

TABLE 2

TAXONOMY OF WRITING CHANGE FUNCTIONS ADOPTED FROM Li \& KIM (2016)

\begin{tabular}{ll}
\hline Writing Change Functions & Definitions \\
\hline Adding & Adding or contributing new content or texts initially produced by peers or self \\
Correcting & Correcting grammatical errors or other mistakes on language mechanics by peer or self \\
Deleting & Eliminating content or texts initially produced by peers or self \\
Rephrasing & Expressing ideas in different words but keeping original meaning, by peer or self \\
Reordering & Restructuring content or reorganizing ideas by moving texts around content \\
\hline
\end{tabular}


TABLE 3

TAXONOMY OF LANGUAGE FUNCTIONS ADOPTED FROM LI \& KIM (2016)

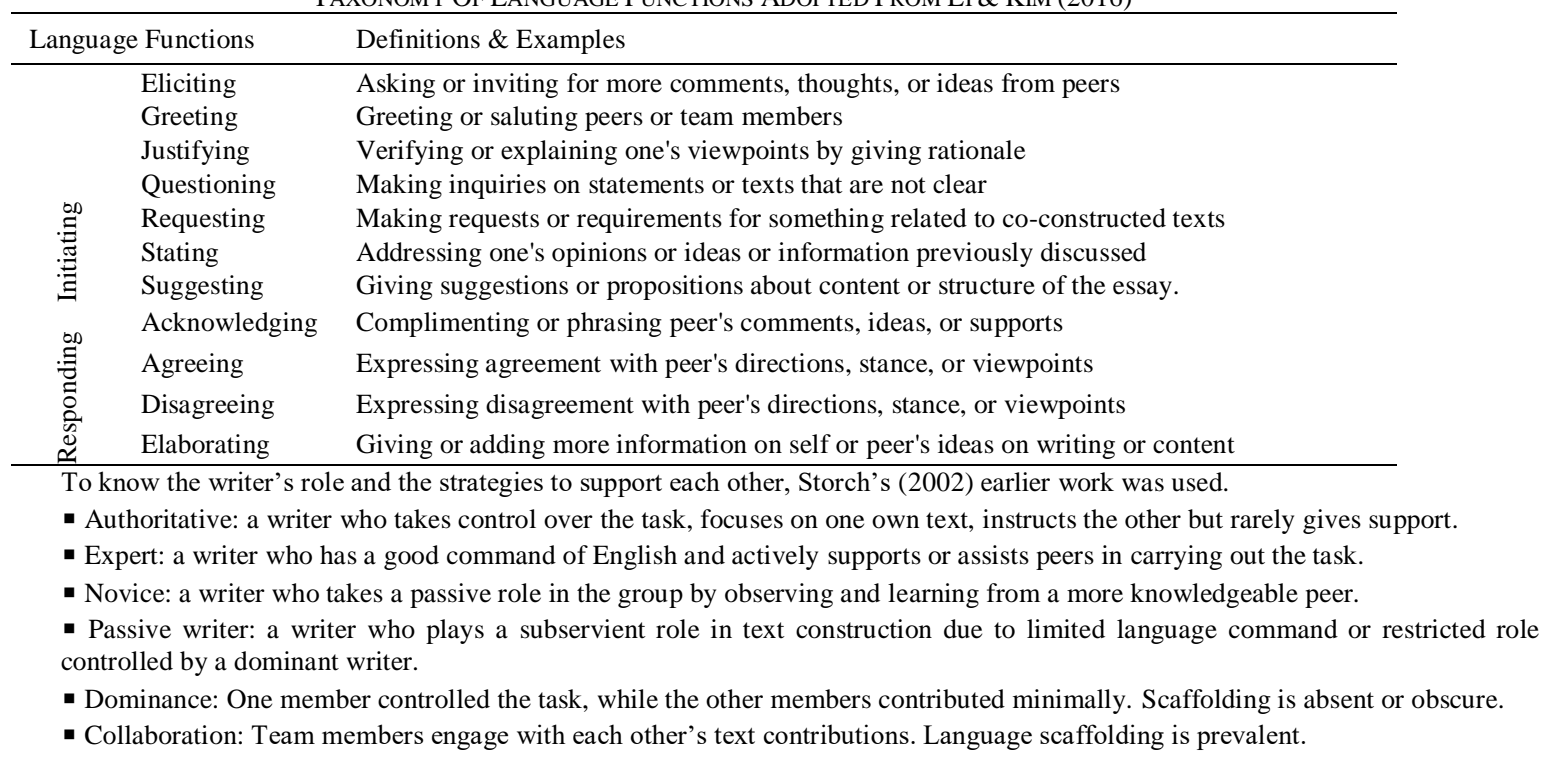

\section{FINDINGS}

To respond to Research Question 1, we analyzed how members employed WCFs and LFs on task negotiation, and the number of text contributions made by individual members. We calculated frequency counts of WCFs and LFs each member contributed to both tasks in Tables 4 and 5. The percentage of text contributions, WCFs, and LFs contributions are presented in Table 6.

TABLE 4

Writing Change Functions In Two Cw TASKs PERFORMEd By SMALl GrouPS

\begin{tabular}{|c|c|c|c|c|c|c|c|c|c|}
\hline \multirow[b]{2}{*}{ Task 1: Description } & & \multicolumn{4}{|c|}{ Group 1} & \multicolumn{4}{|c|}{ Group 2} \\
\hline & & Noah & Sopa & Samart & Total & Aung Win & Danudet & Tommy & Total \\
\hline \multirow{2}{*}{ Adding } & Self & 25 & 11 & 14 & \multirow{2}{*}{65} & 6 & 2 & 13 & \multirow{2}{*}{24} \\
\hline & Other & 14 & 0 & 1 & & 0 & 0 & 3 & \\
\hline \multirow{2}{*}{ Correcting } & Self & 9 & 7 & 6 & \multirow{2}{*}{31} & 3 & 0 & 1 & \multirow{2}{*}{6} \\
\hline & Other & 7 & 1 & 1 & & 0 & 0 & 2 & \\
\hline \multirow{2}{*}{ Deleting } & Self & 9 & 5 & 7 & \multirow{2}{*}{27} & 3 & 1 & 6 & \multirow{2}{*}{15} \\
\hline & Other & 5 & 0 & 1 & & 1 & 0 & 4 & \\
\hline \multirow{2}{*}{ Reordering } & Self & 2 & 3 & 5 & \multirow{2}{*}{12} & 1 & 0 & 0 & \multirow{2}{*}{1} \\
\hline & Other & 1 & 0 & 1 & & 0 & 0 & 0 & \\
\hline \multirow{2}{*}{ Rephrasing } & Self & 6 & 1 & 2 & \multirow{2}{*}{14} & 5 & 1 & 7 & \multirow{2}{*}{15} \\
\hline & Other & 4 & 1 & 0 & & 0 & 0 & 2 & \\
\hline Total & & 82 & 29 & 38 & 149 & 19 & 4 & 38 & 61 \\
\hline \multicolumn{10}{|l|}{ Task 2: Argument } \\
\hline \multirow{2}{*}{ Adding } & Self & 17 & 9 & 6 & \multirow{2}{*}{42} & 7 & 0 & 15 & \multirow{2}{*}{26} \\
\hline & Other & 9 & 1 & 0 & & 1 & 0 & 3 & \\
\hline \multirow{2}{*}{ Correcting } & Self & 2 & 2 & 3 & \multirow{2}{*}{12} & 3 & 0 & 6 & \multirow{2}{*}{12} \\
\hline & Other & 4 & 1 & 0 & & 1 & 0 & 2 & \\
\hline \multirow{2}{*}{ Deleting } & Self & 7 & 3 & 4 & \multirow[b]{2}{*}{16} & 1 & 0 & 3 & \multirow{2}{*}{7} \\
\hline & Other & 2 & 0 & 0 & & 0 & 0 & 3 & \\
\hline \multirow{2}{*}{ Reordering } & Self & 3 & 4 & 1 & \multirow{2}{*}{10} & 0 & 0 & 0 & \multirow{2}{*}{0} \\
\hline & Other & 2 & 0 & 0 & & 0 & 0 & 0 & \\
\hline \multirow{2}{*}{ Rephrasing } & Self & 12 & 0 & 2 & & 4 & 0 & 5 & \\
\hline & Other & 5 & 0 & 0 & 19 & 0 & 0 & 1 & 10 \\
\hline Total & & 63 & 20 & 16 & 99 & 17 & 0 & 38 & 55 \\
\hline
\end{tabular}


TABLE 5

LANGUAGE FUNCTIONS PERFORMED BY SMALL GROUPS

\begin{tabular}{|c|c|c|c|c|c|c|c|c|c|c|c|c|c|c|c|c|c|}
\hline \multirow{3}{*}{\multicolumn{2}{|c|}{ Language Functions }} & \multicolumn{8}{|c|}{ Group 1} & & \multicolumn{7}{|c|}{ Group 2} \\
\hline & & \multicolumn{2}{|c|}{ Noah } & \multicolumn{2}{|c|}{ Sopa } & \multicolumn{2}{|c|}{ Samart } & \multicolumn{2}{|c|}{ Total } & \multicolumn{2}{|c|}{ Aung Win } & \multicolumn{2}{|c|}{ Danudet } & \multicolumn{2}{|c|}{ Tommy } & \multicolumn{2}{|c|}{ Total } \\
\hline & & $\mathrm{T} 1$ & $\mathrm{~T} 2$ & $\mathrm{~T} 1$ & $\mathrm{~T} 2$ & $\mathrm{~T} 1$ & $\mathrm{~T} 2$ & $\mathrm{~T} 1$ & $\mathrm{~T} 2$ & $\mathrm{~T} 1$ & $\mathrm{~T} 2$ & $\mathrm{~T} 1$ & $\mathrm{~T} 2$ & $\mathrm{~T} 1$ & $\mathrm{~T} 2$ & $\mathrm{~T} 1$ & $\mathrm{~T} 2$ \\
\hline \multirow{7}{*}{ : } & Eliciting & 6 & 2 & 0 & 2 & 3 & 0 & 9 & 4 & 0 & 0 & 0 & 0 & 0 & 2 & 1 & 2 \\
\hline & Greeting & 8 & 2 & 2 & 2 & 2 & 0 & 12 & 4 & 0 & 1 & 0 & 0 & 0 & 1 & 0 & 2 \\
\hline & Justifying & 0 & 0 & 0 & 0 & 0 & 0 & 0 & 0 & 0 & 1 & 0 & 0 & 0 & 1 & 0 & 2 \\
\hline & Questioning & 0 & 3 & 3 & 0 & 0 & 1 & 3 & 4 & 0 & 0 & 0 & 0 & 1 & 1 & 1 & 1 \\
\hline & Requesting & 6 & 8 & 0 & 3 & 1 & 0 & 7 & 11 & 0 & 0 & 0 & 0 & 0 & 1 & 0 & 1 \\
\hline & Stating & 9 & 10 & 1 & 3 & 1 & 1 & 11 & 14 & 2 & 1 & 1 & 0 & 2 & 3 & 4 & 4 \\
\hline & Suggesting & 8 & 4 & 1 & 0 & 0 & 0 & 9 & 4 & 1 & 0 & 0 & 0 & 2 & 2 & 3 & 2 \\
\hline \multirow{5}{*}{ 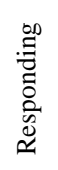 } & Acknowledging & 6 & 1 & 1 & 1 & 1 & 0 & 8 & 2 & 1 & 0 & 0 & 0 & 1 & 0 & 2 & 0 \\
\hline & Agreeing & 3 & 1 & 5 & 2 & 8 & 1 & 16 & 4 & 1 & 2 & 0 & 0 & 1 & 0 & 2 & 2 \\
\hline & Disagreeing & 1 & 3 & 0 & 0 & 0 & 0 & 1 & 3 & 0 & 0 & 0 & 0 & 0 & 0 & 0 & 0 \\
\hline & Elaborating & 3 & 4 & 1 & 0 & 1 & 0 & 5 & 4 & 0 & 0 & 0 & 0 & 0 & 2 & 0 & 2 \\
\hline & Total & 50 & 38 & 14 & 13 & 17 & 3 & 81 & 54 & 5 & 5 & 1 & 0 & 7 & 13 & 13 & 18 \\
\hline
\end{tabular}

TABLE 6

LEARNERS' TEXT CONTRIBUTIONS, WCFS, AND LFS CONTRIBUTIONS IN PERCENTAGES

\begin{tabular}{|c|c|c|c|c|c|c|c|c|c|c|c|c|c|}
\hline \multirow[t]{2}{*}{ Group } & \multirow[t]{2}{*}{ Pseudonym } & \multicolumn{2}{|c|}{$\begin{array}{c}\text { Text } \\
\text { contribution } \\
\text { (words) }\end{array}$} & \multicolumn{2}{|c|}{$\begin{array}{c}\text { Text } \\
\text { contributions } \\
(\%)\end{array}$} & \multicolumn{2}{|c|}{$\begin{array}{c}\text { WCFs } \\
\text { contributions } \\
(\%)\end{array}$} & \multicolumn{2}{|c|}{$\begin{array}{c}\text { LFs } \\
\text { contributions } \\
(\%)\end{array}$} & \multicolumn{2}{|c|}{$\begin{array}{l}\text { Group WCFs } \\
\text { contributions on } \\
\text { other texts }(\%)\end{array}$} & \multicolumn{2}{|c|}{$\begin{array}{l}\text { Group LCFs } \\
\text { contributions on } \\
\text { responding acts } \\
(\%)\end{array}$} \\
\hline & & $\mathrm{T} 1$ & $\mathrm{~T} 2$ & T1 & $\mathrm{T} 2$ & $\mathrm{~T} 1$ & $\mathrm{~T} 2$ & $\mathrm{~T} 1$ & $\mathrm{~T} 2$ & T1 & $\mathrm{T} 2$ & T1 & $\mathrm{T} 2$ \\
\hline \multirow{3}{*}{ G1 } & Noah & 647 & 664 & 73 & 73 & 55 & 64 & 62 & 70 & & & & \\
\hline & Sopa & 121 & 182 & 14 & 15 & 19 & 20 & 17 & 24 & 26 & 24 & 59 & 32 \\
\hline & Samart & 115 & 157 & 13 & 12 & 26 & 16 & 21 & 6 & & & & \\
\hline \multirow{3}{*}{ G2 } & Aung Win & 194 & 123 & 27 & 18 & 31 & 31 & 38 & 28 & & & & \\
\hline & Danudet & 0 & 0 & 0 & 0 & 7 & 0 & 8 & 0 & 20 & 20 & 44 & 29 \\
\hline & Tommy & 534 & 579 & 73 & 82 & 62 & 69 & 54 & 72 & & & & \\
\hline
\end{tabular}

Interaction Patterns

The group interaction patterns were drawn from the degree of equality and mutuality mirrored in three aspects; members' use of LFs for negotiating on tasks, use of WCFs, and scaffolding offered to each other during the CW process. The following present interaction patterns of small group collaboration.

\section{A. Group 1: Expert/Novice (Task 1) - Expert/Novice (Task 2)}

Group 1 consisted of one female from Cambodia (Sopa) and two male students from the Philippines (Noah) and Thailand (Samart). In Task 1, the group jointly composed a descriptive essay, "The Beauty of Southeast Asian Countries". Noah led the team, designated clear roles to the members, and scaffolded his peers concerning language issues. The team exhibited mutual engagement in text construction (reflected by their use of WCFs: 38 instances made on other text, and LFs: 51 initiating acts versus (vs) 30 responding acts, see Table 5). Noah served as an expert to assist the teammates with language issues. In Task 2, the group interaction pattern remained stable when the team constructed their argument essay, "College Education and Being Successful". The triad generated 99 WCFs (75 instances on selftext and 24 instances on other text, see Table 4). Like Task 1, Noah produced the most WCFs (64\%), and his text contribution accounted for $73 \%$ (see Table 6). The group generated 54 acts of LFs: 41 initiating acts vs 13 responding acts in Task 2. The extended use of LFs and WCFs made on other texts implied that they engaged with others' work. Some examples of the team utilization of WCFs and LFs are illustrated in Figure 2. 


\begin{tabular}{|c|c|c|}
\hline 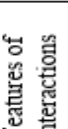 & $\begin{array}{l}\text { CW Task } 1 \text { (Description) } \\
\text {-Noah: } 82 ; \text { Sopa: } 29 \text {; Samart: } 38 \\
\text { - } 111 \text { Self vs } 38 \text { Other } \\
\text { Examples }\end{array}$ & $\begin{array}{l}\text { CW Task } 2 \text { (Argument) } \\
\text {-Noah: } 63 ; \text { Sopa: } 20 \text { : Samart: } 16 \\
\text { - } 75 \text { Self vs } 24 \text { Other } \\
\text { Examples }\end{array}$ \\
\hline 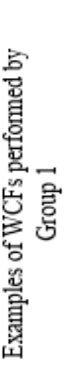 & $\begin{array}{l}\text { Sopa wrote: The Angkor Wat is the most visit two times } \\
\text { a year when the morning bright sun rises which makes it } \\
\text { look spectacular. } \\
\text { Noah corrected: The Angkor Wat is most visited by } \\
\text { tourists twice a year when the bright morning sun } \\
\text { rises which makes the temple look spectacular. } \\
\text { (correcting other) } \\
\text { Samart wrote: I would like to devote myself to } \\
\text { Buddhist. And the last is King: He loves and appreciate } \\
\text { the divine grace of the king (Rama IX) } \\
\text { Noah corrected: He devoted himself to Buddhism; } \\
\text { King, as his love passed through the late king } \\
\text { (Rama IX). (correcting and rephrasing, other) }\end{array}$ & $\begin{array}{l}\text { Samart wrote: Mark Zuckerberg, owner of Facebook. } \\
\text { According to the information from the biography website } \\
\text { said that he did not graduate from college. } \\
\text { Noah rephrased and added; Facebook's Chief } \\
\text { Executive Officer and Founder, is a Harvard } \\
\text { university drop out who was able to make fortunes } \\
\text { deciding to make a path for himself outside college. } \\
\text { (rephrasing and adding, other) } \\
\text { Sopa wrote: There are various reasons why having a college } \\
\text { degree is not essential } \\
\text { Noah added: There are various reasons why having a } \\
\text { college degree is not essential to being successful since } \\
\text { a lot of successful people do not have a college degree. } \\
\text { (adding, other) }\end{array}$ \\
\hline 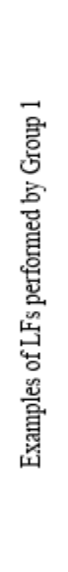 & $\begin{array}{l}\text {-Noah: } 50 \text {; Sopa: } 14 \text {; Samart: } 17 \\
\text { - } 51 \text { initiating and } 30 \text { responding acts } \\
\text { Examples } \\
\text { Noah: Hi friends! You can call me Joe. We can work } \\
\text { together on this platform. } \\
\text { Samart: Hi Joe, Iust call me Mart. Yes we can work here. } \\
\text { Sopa: Nice to get to now you. I'm Need from Cambodia. } \\
\text { (greeting, suggesting, greeting, agreeing, acknowledging, } \\
\text { greeting) } \\
\text { Noah: I've got an idea, we can describe our favorite place } \\
\text { in our countries, so we can get three different places. } \\
\text { Samart: I agree Joe. } \\
\text { Sopa: Me too. What is our topic? } \\
\text { Noah: We can make it something like the beauty of } \\
\text { Southeast Asian Countries. } \\
\text { Sopa: Okay, you can lead us, Joe. } \\
\text { Noah: Yes, but we can work together. Don't worry. } \\
\text { Samart: OK } \\
\text { (stating, suggesting, agreeing, agreeing, questioning, } \\
\text { suggesting, agreeing, suggesting, agreeing, stating. } \\
\text { agreeing) }\end{array}$ & $\begin{array}{l}\text {-Noah: } 38 \text {; Sopa: } 13 \text {; Samart: } 3 \\
\text { - } 41 \text { initiating and } 13 \text { responding acts } \\
\text { Examples } \\
\text { Noah; Hi friends! Please think of } 3 \text { arguments and } 1 \text { rebuttal } \\
\text { of your chosen topic, so we'11 weigh things on what looks } \\
\text { better. } \\
\text { Sopa: Thank you for reminding us. We'11 share ideas and } \\
\text { look at them together then. } \\
\text { Noah: Great! } \\
\text { (greeting, requesting, acknowledging, stating, acknowledging) } \\
\text { Noah: This is my suggestion: "How Necessary is a College } \\
\text { Education?" the arguments are, having a college degree } \\
\text { doesn't guarantee you a job right away, some people like } \\
\text { Bill Gates and Mark Zuckerberg have no college degree. } \\
\text { Sopa: Okay we can work on this topic and you can lead us } \\
\text { again like the first one. } \\
\text { Noah: Of course, and Mart, please start the intro and we'11 } \\
\text { edit that later when you're done with it. } \\
\text { Samart: Yes, Joe I can do that. } \\
\text { (suggesting, elaborating, agreeing, suggesting, agreeing, } \\
\text { requesting, agreeing) }\end{array}$ \\
\hline  & $\begin{array}{l}\text { Direction maintenance / Intersubjectivity } \\
\text { Google Docs version history revealed Noah supported his } \\
\text { team with language issues: correcting grammar and tenses; } \\
\text { providing both direct and indirect feedback; designating } \\
\text { clear roles to members. } \\
\text { For example, in the WCFs, Noah corrected Samart's } \\
\text { text and in the comment history he explained why he } \\
\text { changed I to He in describing in a third person viewpoint. } \\
\text { He corrected verb form from "most visit" to "most visited" } \\
\text { and informed Sopa that the phrase is in passive form. }\end{array}$ & $\begin{array}{l}\text { Instructing/Intersubjectivity } \\
\text { Noah asked his team to come up with arguments and rebuttal } \\
\text { and shared his points. He rephrased Samart's text and } \\
\text { left a comment in the GD comment window that the } \\
\text { writing needs to paint a clearer picture and spelling it out. } \\
\text { Noah added text to Sopa's sentence and reminded her to } \\
\text { give example to show to readers. } \\
\text { The GD archive showed sufficient evidences of peer } \\
\text { scaffolding }\end{array}$ \\
\hline
\end{tabular}

Figure 2. Characteristic Features of Interactions Produced by Group 1

(*Note. Excerpts are from the original texts. Errors on language were not corrected.)

As seen from excerpts in Figure 2, Noah positioned himself as an expert, directed the team, and scaffolded his peers. He interacted actively with his peers' texts as evidenced by his extended use of WCFs on other texts ( 31 instances in Task 1 and 22 instances in Task 2). Furthermore, the team produced various LFs ( 81 acts in Task 1 and 54 acts in Task 2), and the initiating acts were received and responded to. The GD archives revealed that Noah scaffolded his teammates by giving them both metalinguistic feedback (providing additional information with some explanation) and corrective feedback (overriding text scripts with correct forms on his peers' sentences). Furthermore, he left comments in the GD comment box to communicate with his team, as reflected by his frequent use of LFs in both tasks. Sopa and Samart, on the other hand, positioned themselves as novice writers profiting from the group writing process. The team developed good rapport (see the excerpt of LFs used in both CW Tasks when Noah greeted his peers "Hi friends!" or called Sopa's nickname "Need", or when Samart called Noah's nickname "Hi Joe"). Although members' text contributions to writing products were unbalanced as the leader did more work, the collaborative efforts benefited the novice writers, for they received support from the leader. Data analysis from GD version history along with members use of WCFs and LFs revealed that Group 1 interaction patterns fall into Quadrant 4 of Storch's interaction model, which represents moderate to low equality (proportion of text contributions) but moderate to high mutuality (engagement with other's texts reflected by their use of WCFs on other text and initiating and responding acts of LFs).

\section{B. Group 2: Authoritative/Withdrawn (Task 1) - Authoritative/Withdrawn (One Member Failed to Participate) (Task 2)}

Group 2 consisted of three males from Malaysia, Myanmar, and Thailand. In Task 1, the team composed a descriptive essay, "Life in a university". The analysis from the GD archive revealed that Tommy led the group and was later joined by his peers. To some extent, the team interacted with others' texts as reflected by their use of WCFs (49 instances on self-text and 12 on other text, Table 4) and LFs (9 initiating acts vs 4 responding acts, see Table 5), but task negotiation was orchestrated by two members. Danudet withdrew from the group during the collaboration process. 
Tommy did most of the work (73\%) with minimal support from Aung Win (27\%) in Task 1 (see Table 6). In Task 2, the group CW style remained unchanged: Tommy controlled the task (82\%), whereas Danudet failed to join his team. Thus, the team CW efforts in Task 2 failed since one member was absent.

From excerpts in Figure 3, Tommy dominated the tasks and directed his team. The analysis from GD archives revealed that Tommy controlled the writing, instructed his peers but failed to designate responsibilities or scaffold his peers. He did not elucidate correct forms of language structures when he removed his peer's texts. Tommy's authoritative role resulted in the withdrawal of a member. Consequently, the team $\mathrm{CW}$ efforts became inefficacious due to the lack of member engagement. As illustrated in the excerpts in Figure 3 in CW Task 2, Tommy asked questions twice and gave a comment addressed to Aung Win but did not receive response. This occurrence indicated that the member did not have any affective involvement (Lidz, 1991) on other's texts. Furthermore, singular pronoun (e.g., I, you, your) were extendedly employed, indicating that the members did not develop a sense of belonging that could push them to work more collectively. For example, Tommy commented, "What can be your description or strong adjective to describe this of your sentence? Aung Win responded, "I'll rewrite this", or when Tommy remarked, "Here you have no counterclaim to support", and received no response (see excerpt in Figure 3). This dyadic interaction did not promote bonds of friendship but rather reduced joint attention. The analysis from GD history archives revealed that Tommy acted more in an authoritative role. He even used his alias "Commander" while performing tasks. From the analysis of text construction through members' use of WCFs and LFs as revealed in GD history, Group 2 interaction patterns fit into Quadrant 3, which represents moderate to low equality of text contributions and moderate to low mutuality of engagement with each other's work marked by members' use of WCFs on other text and initiating and responding acts of LFs. Examples of the team employment of WCFs and LFs are shown in Figure 3.



To succinctly explain the occurrence of the groups' CW behaviors across tasks, we could summarize the findings in Figure 4. 


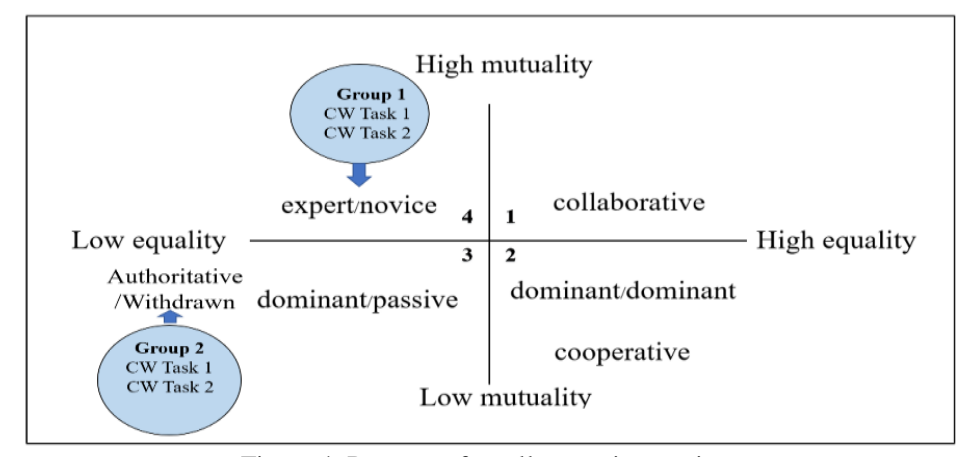

Figure 4. Patterns of small group interaction

To address our second research question, we explored why these two small groups involved in two CW essays, given the same amount of time, exhibited distinctive interaction patterns. We coded and categorized meanings from the semistructured interviews to elicit themes that illustrate the group members' patterns of interaction. There were four major themes identified: (1) individual goals, (2) learners' English proficiency, (3) individual roles, and (4) agency.

\section{Individual Goals}

Four convergent goals emerged from our qualitative data analysis concerning fluidity of interaction patterns and CW styles: (1) getting a good grade, (2) producing a good quality essay, (3) improving writing skills, and (4) improving communication skills. These goals influenced interactions and contributions to group work. Members with a determined goal of getting a good grade and producing a good quality essay occupied more writing space and contributed more texts. This assertion was supported by learners' comments in the interviews. Noah (Group 1) expressed his goal of CW tasks that,

Two main goals I have when I collaborated with our team, which are acceptable quality of work and pass the course with a flying color grade at the end of the semester.

Likewise, Tommy (Group 2) echoed his personal goal in the interview,

If you ask me even like it or not, I need to do my part for I need to get a good GPA for my first year in college.

Whereas passive writer like Samart (Group 1) shared that he collaborated with his team to improve writing and enhance communication skills. Samart shared in the interview,

As for me I believe that writing together will improve writing skills, particularly for me and I can learn from my friends.

The findings were in line with previous studies (Alhadabi \& Karpinski, 2020; Wang, 2019), where learners with a determined goal of earning good grades were found to pay more attention to academic performance and to be actively engaged in group activities.

\section{Learners' English Proficiency Level}

Learners with higher language proficiency level took a more active role in $\mathrm{CW}$ since they have a distinct advantage over their less capable peers concerning linguistic resources and language skills. Their language competency helped them express thoughts more conveniently, and they could rectify language errors faster. On the contrary, learners with lower language proficiency were reluctant to contribute for fear of making errors. Samart's (Group 1) and Danudet's (Group 2) interviews supported this assertion that their English proficiency is low and limited in vocabulary knowledge, resulting in a reluctance to write or contribute.

I did not write a lot because my vocabulary in English is very limited when I compare myself to my group.

(Samart's statement from the interview).

Maybe it is better for me if I work with a Thai friend who can help me because my grammar is bad. These international students have good English and I feel a little bit shy to work with them. (Danudet's comment from the interview).

This finding implied that learners with limited linguistic resources passively contributed to the group task or even claimed to be a part of the group although their contributions might be insignificant; on the contrary, competent writers would produce more language-related episode and put more effort into the work.

\section{Individual Roles}

Individual members in the group played a vital role in shaping interaction patterns and collaborative efforts. In the present study, Group 1 appeared to work more collectively. The leader was designated an apparent role and responsibility by his members. The GD history archives revealed that the team assigned sections to be completed by certain members. Consequently, the member interaction is positive. In contrast, the leader in Group 2 failed to designate responsibility for his members to write. This incident was reflected by Aung Win's statement in his interview,

In my group, someone took control of the work, but I was not told properly which part I need to help him. (Aung Win's remark from the interview) 
Danudet also echoed a similar view concerning the role of a member in group work,

If I know my work and what I must do and the group can tell me, I can try but I need their help too because I can't write well like them. (Danudet's statement from the interview)

This finding informed us that to produce an effective OCW task, the group must have a supportive leader who focuses not only on self-written texts but also interacts with peers' work, gives constructive feedback, and designates clear roles to the teammates.

\section{Agency}

Agency is defined as learners' attunements to make crucial decisions that contribute to the group goals of the imposed activity (Nolen et al., 2011). In this study, we investigated specific pronouns (e.g., I, he, she, you, they, we, and our,) used by each team in GD archives comment history, and from the interviews to extract the socially mediated agency either individual agency or collaborative agency. We found that Group 1 used both individual and collaborative agencies across tasks, whereas Group 2 employed more individual agency. Both individual agency and collaborative agency produced by Group 1 for task negotiations are illustrated in excerpts in Figure 2. For instance, in LFs, Noah commented in Task 1, "we can describe our favorite place in our countries" or when he called Sopa's nickname, "Yes, Need but we can work together". The use of collective agency personal pronouns could drive the team in collaborative endeavors and improve social interactions. On the contrary, the individual agency enforces learners to take actions in pursuit of their goals with less considerate of others' (Li \& Zhu, 2017). For instance, in Figure 3 of CW Task 2, Tommy commented, "If you insist, I will change your paragraph", or when he asked Aung Win to read the text, "Can you read your tiny paragraph? or gave an instruction, "make sure you take the source". The members used individual agency extendedly in the interviews. For example, Danudet stated, "Maybe it is better for me if I work with a Thai friend". These tones of language do not promote collective efforts. Therefore, the use of these individual agency personal pronouns (e.g., I, you, he, they) reduced social bonding and joint attention (Hanjani \& $\mathrm{Li}, 2014$ ). This incident might affect the emotional response, and consequently, initiating acts were not responded.

\section{Discussion}

This study aimed to investigate small group interaction patterns and factors that influence team collaborations in doing OCW tasks. Learners, in small groups, completed writing tasks of the same genre in the same length of time, in an online setting; however, each group exhibited distinctive interactions, but each team's interaction patterns remained similar across tasks. Small group orchestrating stable patterns of interaction across $\mathrm{CW}$ tasks on a web-based writing platform were also reported in previous studies (e.g., Elabdali \& Arnold, 2020). These studies reported that L2 learners in small groups, particularly when members are heterogeneous in language proficiency levels, would take their fixed roles in group writing, which remained unchanged even as the task progressed. Such finding contrasts $\mathrm{Li}$ and Kim (2016), whose study found changes in interaction patterns when task-types shifted. In our study, members with higher language proficiency made a more significant contribution to the quality of the writing tasks and provided notable WCFs and LFs across tasks, which was also reported in Li (2013) and Hsu's (2020) studies. Nevertheless, one prominent writer using extended LFs unilaterally does not necessarily promote collaborative endeavors.

In the present study, Group 1 worked more collectively based on their trilateral efforts, clear roles and responsibilities, and task completion engagement. The team leader in Group 1 scaffolded his peers by demonstrating affective involvement in others' work, providing suggestions to resolve language errors, offering both direct and indirect feedback, and intersubjectivity was apparent. Members were reinforced and given the 'intellectual push' to work at the outer limits of their potentiality (Hammond \& Gibbons, 2005) or zone of proximal development (ZPD) (Vygotsky, 1978). As a result, the less-abled learners gave it a try despite the language barrier they struggled with, as observed in Group 1. In contrast, the team whose leader showed an authoritative role, dominated the task would lack intersubjectivity. The absence of peer scaffolding and obscure roles and responsibility of members could demotivate the less proficient group members, resulting in them to withdraw from the team, as seen in the case of Danudet in Group 2. Thus, more knowledgeable peer scaffoldings play a vital role in shaping team interaction and collaboration.

Aside from members' engagement, scaffolding strategies, and collaborative efforts, our triangulated data source from interviews explained factors influencing team collaborations. These factors include individual goals, learners' language proficiency, individual roles, and use of agency. In particular, our case study revealed that learners' intent on getting a good grade put in more effort and took their work more seriously. In contrast, learners whose aims were to improve writing and communication skills held different viewpoints, which were that grades are not necessary to achieve success.

A further finding revealed that learners' language proficiency shaped collaborative group behavior. Learners with a good command of English were more proactive in CW than others, for they have broader linguistic resources. Their language privilege allowed them to express thoughts and share texts more freely. Consequently, their contributions positively influenced the writing product. In contrast, learners with lower language proficiency hesitated to share texts for fear of making mistakes. These findings were in line with previous studies (e.g., Dong \& Liu, 2020; Hsiu-Chen, 2019) which reported that high-skilled learners produced more texts, invested more efforts into group work, and were able to identify language problems more successfully. In contrast, less-skilled writers passively did their parts for fear of violating basic grammar rules (Zhang, 2019). This incident was observed when Tommy did not scaffold his peers but 
removed others' texts without explanations, ensuing Danudet to withdraw from his team for not receiving language scaffolding as opposed to Samart in Group 1 who was supported by his team leader. This phenomenon echoed the work of Hsu (2020), who found that when peer interaction lacked intersubjectivity or scaffolding, the less-abled partner would gradually withdraw from work.

The results of our case study also revealed that collaborations became more collective and engaging when the group experienced emergent leadership. This similar finding was in line with Kukulska-Hulme (2004), who found that groups whose leaders focused on task completion and member satisfaction worked more effectively. In other words, a more effective group is directed by a relationship-focused leader who values individual contributions. The team with a relationship-focused leader would likely exhibit expert/novice interaction patterns since the leader of this type would support the members and offer helps with language concerns (Elabdali \& Arnold, 2020). Our findings informed us that a team needs a committed leader who can motivate the members to fulfill the group goals, designate a clear role for each member, and intervene in members' contributed texts.

Lastly, our findings revealed that individual and collaborative agency helped shape interaction patterns. The use of first person plural subject pronouns such as "we" or "our" implied that the team members established joint ownership (Li, 2014; Wang, 2019). The use of collaborative agencies (e.g., we, our, us) is perceived to bring close emotional ties to others, leading to more positive interactions. In contrast, individual agency (e.g., you, he, she, my) can decrease positive interaction. Our study observed members employing either individual or collaborative agency while interacting on tasks. From the interviews, we found that Group 1 used collaborative agency (e.g., we, our, or peer's nickname) extendedly, whereas Group 2 deployed individual agency (e.g., I, you, them), which decreased their interactions and a lower sense of belonging.

\section{CONCLUSION AND RECOMMENDATIONS}

This study further extends the body of literature and research in OCW by investigating small group interaction patterns and factors influencing team collaborations in an English composition class with learners from diverse cultural backgrounds. The findings document how members in small groups collaborated distinctly in completing essays via GD. The results of this study indicated that collaborations help catalyze team members to work more collectively, which demonstrated an expansion of the use of WCFs on other members' texts; how LFs are initiated and responded to; and scaffolding strategies provided by a group leader. All of these were shaped by individual members' goals, language proficiency, members' transparent roles, and use of collaborative agency. The study also provided evidence that the ZPD may be evident even among students at the same study level. In this regard, our study has highlighted that an online setting may offer a reconceptualization of those who are privileged to offer support.

As an embedded case study, the current research has its limitations. Future studies may consider investigating a broader range of CW tasks with other types of writing genres that may influence group writing processes, interaction patterns, and quality of jointly composed texts. Another limitation in the current study is that participants remained in the same group for both tasks. Future research may consider exploring how changing group partners would affect aspects of collaboration and the quality of work. Furthermore, future research may consider longitudinal approaches to gather richer data. The scope of technology used may also be expanded to other social media messaging platforms to examine the correlation between social support and task completion in a virtual environment. These studies have the potential of providing recommendations for synchronous or asynchronous learning environments, in the event that sudden shifts in teaching mode become necessary, such as that observed in the current pandemic.

\section{REFERENCES}

[1] Abe, M. (2020). Interactional practices for online collaborative writing. Journal of Second Language Writing, 49,100752. https://doi.org/10.1016/j.jslw.2020.100752

[2] Afify, M. K. (2019). The influence of group size in the asynchronous online discussions on the development of critical thinking skills, and on improving students' performance in online discussion forum. International Journal of Emerging Technologies in Learning, 14(5), 132-152.

[3] Alghasab, M., Hardman, J., \& Handley, Z. (2019). Teacher-student interaction on wikis: Fostering collaborative learning and writing. Learning, Culture and Social Interaction, 21, 10-20.

[4] Alhadabi, A., \& Karpinski, A. C. (2020). Grit, self-efficacy, achievement orientation goals, and academic performance in university students. International Journal of Adolescence and Youth, 25(1), 519-535.

[5] Andrew, M. (2019). Collaborating online with four different google apps: Benefits to learning and usefulness for future work. Journal of Asia TEFL, 16(4), 1268-1288.

[6] Chen, W. (2019). An exploratory study on the role of L2 collaborative writing on learners' subsequent individually composed texts. The Asia-Pacific Education Researcher, 28(6), 563-573.

[7] Dobao, A. F. (2014). Attention to form in collaborative writing tasks: Comparing pair and small group interaction. Canadian Modern Language Review, 70(2), 158-187.

[8] Dong, Y., \& Liu, S. (2020). Dynamic features of students' scaffolding interaction in English writing class. Theory and Practice in Language Studies, 10(6), 647-656. http://dx.doi.org/10.17507/tpls.1006.04

[9] Elabdali, R., \& Arnold, N. (2020). Group dynamics across interaction modes in L2 collaborative wiki writing. Computers and Composition, 58, 1-17. doi.org/10.1016/j.compcom.2020.102607 
[10] Hammond, J., \& Gibbons, P. (2005). Putting scaffolding to work: The contribution of scaffolding in articulating ESL education. Prospect, 20(1), 6-30.

[11] Hanjani, A. M., \& Li, L. (2014). Exploring L2 writers' collaborative revision interactions and their writing achievement. System 44, 101-114. https://doi.org/10.1016/j.system.2014.03.004

[12] Hsiu-Chen Hsu. (2019). Wiki-mediated collaboration and its association with L2 writing development: an exploratory study. Computer Assisted Language Learning, 32 (8), 945-967.

[13] Hsu, H. C. (2020). The impact of task complexity on patterns of interaction during web-based asynchronous collaborative writing tasks. System, 93, 1-13. https://doi.org/10.1016/j.system.2020.102328

[14] Kessler, G., Bikowski, D., \& Boggs, J. (2012). Collaborative writing among second language learners in academic web-based projects. Language Learning \& Technology, 16 (1), 91-109.

[15] Krishnan, J., Yim, S., Wolters, A., \& Cusimano, A. (2019). Supporting online synchronous collaborative writing in the secondary classroom. Journal of Adolescent \& Adult Literacy, 63(2), 135-145.

[16] Kukulska-Hulme, A. (2004). Do online collaborative groups need leaders? In T. Roberts (Ed.), Online collaborative learning. Theory and practice (pp. 262-280). Hershey, PA: Information Science Publishing.

[17] Langan, J., \& Albright, Z.L. (2019). College writing skills with reading (10 ${ }^{\text {th }}$ Ed.). New York: McGraw-Hill Companies.

[18] Lee, K. Y., \& Hassell, D. G. (2021). Students' attitudes and preferences towards Google Docs as a collaborative writing platform. International Journal of Computer-Assisted Language Learning and Teaching, 11(2), 1-15.

[19] Li, M. (2013). Individual novices and collective experts: Collective scaffolding in wiki-based small group writing. System, 41(3), 752-769. https://doi.org/10.1016/j.system.2013.07.021

[20] Li, M. (2014). Small group interactions in wiki-based collaborative writing in the EAP context. (Unpublished doctoral dissertation). University of South Florida, FL: USA

[21] Li, M., \& Kim, D. (2016). One wiki, two groups: Dynamic interactions across ESL collaborative writing tasks. Journal of Second Language Writing, 31, 25-42. https://doi.org/10.1016/j.jslw.2016.01.002

[22] Li, M., \& Zhu, W. (2017). Explaining dynamic interactions in wiki-based collaborative writing. Language Learning \& Technology, 21(2), 96-120. https://doi.org/10.1057/978-1-137-51768-5

[23] Lidz, C. S. (1991). Practitioner's guide to dynamic assessment. New York, NY: Guilford Press.

[24] Limbu, L., \& Markauskaite, L. (2015). How do learners experience joint writing: University students' conceptions of online collaborative writing tasks and environments. Computers \& Education, 82, 393-408. https://doi.org/10.1016/j.compedu.2014.11.024

[25] Mahan, K. R. (2020). The comprehending teacher: scaffolding in content and language integrated learning (CLIL). The Language Learning Journal, 1-15. https://doi.org/10.1080/09571736.2019.1705879

[26] Mak, B. \& Coniam, D. (2008). Using wikis to enhance and develop writing skills among secondary school students in Hong Kong. System, 36, 437-455. https://doi.org/10.1016/j.system.2008.02.004

[27] McDonough, K., \& De Vleeschauwer, J. (2019). Comparing the effect of collaborative and individual prewriting on EFL learners' writing development. Journal of Second Language Writing, 44, 123-130.

[28] Nolen, S. B., Ward, C. J., \& Horn, I. S. (2011). Motivation, engagement, and identity: Opening a conversation. In D. McInerney, R. Walker \& G. A. D. Liem (Eds.), Sociocultural theories of learning and motivation: Looking back, looking forward. Greenwich, CT: Information Age Press.

[29] Pritchard, A., \& Woollard, J. (2010). Psychology for the classroom: Constructivism and social learning. Abingdon, UK: Routledge.

[30] Rasmussen, J (2001) The importance of communication in teaching: A systems-theory approach to the scaffolding metaphor. Curriculum Studies, 33 (5), 569-582.

[31] Storch, N. (2002). Patterns of interaction in ESL pair work. Language Learning, 52(1), 119-158.

[32] Storch, N. (2013). Collaborative writing in L2 classrooms. Bristol, UK: Multilingual Matters.

[33] Van Lier, L. (2004). The ecology and semiotics of language learning: A sociocultural perspective. Boston: Kluwer Academic Press.

[34] Vygotsky, L. S. (1978). Mind in society: The development of higher psychological processes. Cambridge, MA: Harvard University Press.

[35] Wang, L. (2019). The impact of computer-mediated contexts on interaction pattern of ESL learners in collaborative writing. Technology, Pedagogy and Education, 28(5), 547-562.

[36] Wingate, U. (2012). 'Argument' helping students understand what essay writing is about. Journal of English for Academic Purposes, 11(2), 145-154.

[37] Woodrich, M., \& Fan, Y. (2017). Google Docs as a tool for collaborative writing in the middle school classroom. Journal of Information Technology Education Research, 16, 391-410

[38] Yanguas, I. (2020). L1 vs L2 synchronous text-based interaction in computer-mediated L2 writing. System, 88, 1-11. https://doi.org/10.1016/j.system.2019.102169

[39] Yin, R. K. (2018). Case study research and applications: Design and methods (6 ${ }^{\text {th }}$ Ed.). Thousand Oaks, CA: SAGE Publications Inc.

[40] Zhang, M. (2019). Towards a quantitative model of understanding the dynamics of collaboration in collaborative writing. Journal of Second Language Writing, 45, 16-30. https://doi.org/10.1016/j.jslw.2019.04.001

[41] Zioga, C., \& Bikos, K. (2020). Collaborative writing using Google docs in primary education: development of argumentative discourse. Turkish Online Journal of Distance Education, 21(1), 133-142. 
Nakhon Kitjaroonchai is a $\mathrm{PhD}$ candidate at School of Foreign Languages, Suranaree University of Technology, Thailand. He currently teaches at Asia-Pacific International University, Thailand. His research interests include online collaborative writing, L2 writing, CALL, and learning motivation.

Suksan Suppasetseree is a full-time lecturer at School of Foreign Languages, Suranaree University of Technology. He earned a $\mathrm{PhD}$ in English Language Studies from Suranaree University of Technology in 2005. His research interests are Technology enhances learning, Computer in education, online learning, computer supported collaborative learning, and instructional design. 